\title{
Emotional Intelligence: A Theoretical Framework for Individual Differences in Affective Forecasting
}

\author{
Michael Hoerger, Benjamin P. Chapman, Ronald M. Epstein, and Paul R. Duberstein \\ University of Rochester
}

\begin{abstract}
Only recently have researchers begun to examine individual differences in affective forecasting. The present investigation was designed to make a theoretical contribution to this emerging literature by examining the role of emotional intelligence in affective forecasting. Emotional intelligence was hypothesized to be associated with affective forecasting accuracy, memory for emotional reactions, and subsequent improvement on an affective forecasting task involving emotionally evocative pictures. Results from two studies $(N=511)$ supported our hypotheses. Emotional intelligence was associated with accuracy in predicting, encoding, and consolidating emotional reactions. Furthermore, emotional intelligence was associated with greater improvement on a second affective forecasting task, with the relationship explained by basic memory processes. Implications for future research on basic and applied decision making are discussed.
\end{abstract}

Keywords: affective forecasting, emotional intelligence, individual differences, memory, decision making

When making significant life decisions, people often wish they could foresee how their choices will impact their future emotional well-being. In fact, people's expectations about emotional reactions to future events can guide decisions about relationships, occupational pursuits, and health behaviors (Gilbert, Pinel, Wilson, Blumberg, \& Wheatley, 1998; Halpern \& Arnold, 2008; Hoerger \& Quirk, 2010; Hoerger, Quirk, \& Weed, in press; Mellers, 2000; Tomlinson, Carmichael, Reis, \& Aron, 2010). To examine the "accuracy" of anticipated emotional reactions, research on affective forecasting (Gilbert et al., 1998) has evaluated the correspondence between people's predicted and actual reactions to emotionally evocative events (e.g., holidays, election outcomes, tenure decisions) and stimuli (e.g., art, prize money, and meals; for a review, see Dunn \& Laham, 2006). These studies reveal that biases in attention, awareness, and understanding of emotions can reduce affective forecasting accuracy (Dunn, Bracket, Ashton-James, Schneiderman, \& Salovey, 2007; Gilbert et al., 1998; Halpern \& Arnold, 2008; Hoerger, Quirk, Lucas, \& Carr, 2009, 2010; Tomlinson et al., 2010; Wilson, Wheatley, Meyers, Gilbert, \& Axsom, 2000).

The need to improve affective forecasting is evident in a range of settings, including health care, education, and finance (Elwyn,

This article was published Online First January 16, 2012.

Michael Hoerger, Benjamin P. Chapman, and Paul R. Duberstein, University of Rochester Medical Center, Department of Psychiatry and Health Care Decision-Making Group; Ronald M. Epstein, University of Rochester Medical Center, Department of Family Medicine and Health Care Decision-Making Group.

This work was supported by T32MH018911 and K08AG031328 from the United States Department of Health and Human Services.

Correspondence concerning this article should be addressed to Michael Hoerger, University of Rochester Medical Center, Department of Psychiatry, 300 Crittenden Boulevard, Rochester, NY 14642. E-mail: Michael_Hoerger@URMC.Rochester.edu
Stiel, Durand, \& Boivin, 2011; Mellers, 2000; Wilson et al., 2000). Basic psychological research designed to elucidate individual differences in affective forecasting can account for sources of error (Tomlinson et al., 2010; Hoerger, Quirk, Chapman, \& Duberstein, in press), which is vital to improving forecasting (Gilbert, Killingsworth, Eyre, \& Wilson, 2009; Hoerger et al., 2010). Acknowledging the importance of prior theoretical contributions to the affective forecasting literature (Gilbert \& Wilson, 2007; Loewenstein \& Lerner, 2003), no theoretical framework has attempted to organize research on individual differences in affective forecasting. Initial studies have explored numerous individual-difference constructs potentially associated with affective forecasting, including the "Big Five" personality traits, attachment styles, cognitive processes, coping strategies, and emotional management (Dunn et al., 2007; Hoerger et al., 2009, 2010; Hoerger \& Quirk, 2010; Tomlinson et al., 2010). Arguably, careful consideration of each of these distinct findings involving individual-difference constructs reveals that they can actually be viewed through the broader lens of emotional-intelligence theory (MacCann \& Roberts, 2008; MacCann, Matthews, Zeidner, \& Roberts, 2003; Mayer, Salovey, \& Caruso, 2002), which can then be used to guide research hypotheses. The present investigation was designed to make a theoretical contribution to research on individual differences in affective forecasting by (a) organizing existing findings within the context of the emotional intelligence literature, and (b) testing theoretically driven hypotheses relating emotional intelligence to incremental improvement in the accuracy of affective judgments.

\section{Framing Prior Research on Individual Differences in Affective Forecasting}

To begin, an emerging consensus has articulated emotional intelligence as a core set of cognitive emotional processes that involve perceiving, using, understanding, and managing emotions 
(MacCann \& Roberts, 2008; Mayer, Caruso, \& Salovey, 1999; Mayer et al., 2002; Mayer, Salovey, Caruso, \& Sitarenios, 2001; Roberts, Zeidner, \& Matthews, 2001). Emotional intelligence is associated with performance on laboratory tasks involving identifying, judging, and reasoning about emotions (Fisher et al., 2010; MacCann \& Roberts, 2008; Mayer, Roberts, \& Barsade, 2008), and has significant and far-reaching ramifications, perhaps facilitating academic achievement, job performance, and social adjustment (Brackett, Rivers, Shiffman, Lerner, \& Salovey , 2006; MacCann et al., 2003; Mayer, Salovey, \& Caruso, 2008). Recent reviews have emphasized that in addition to providing immediate benefits, emotional intelligence may confer further advantages over time. In particular, emotional intelligence could facilitate the longitudinal development of emotional skills, by affording advantages in experiential learning (Brackett et al., 2006; MacCann et al., 2003; Mayer Salovey, \& Caruso, 2008).

Several studies provide indirect evidence for a link between emotional intelligence and affective forecasting skills. Foremost, emotional intelligence involves skills in perceiving one's emotions, and prior research has shown that affective forecasting accuracy is influenced by individual differences in closely related skills, such as mindful awareness (Emanuel, Updegraff, Kalmbach, \& Ciesl, 2010) and attention to ambivalent emotional processes (Hoerger et al., 2010). Second, emotional intelligence involves understanding individual differences in emotional reactivity and coping. Affective forecasting problems often occur when people overlook the impact of their personality, attachment style, and coping processes on emotional reactions (Hoerger \& Quirk, 2010; Hoerger et al., 2009; Quoidbach \& Dunn, 2010; Tomlinson et al., 2010), lapses in insight that potentially occur with less frequency or intensity among individuals who have acquired higher levels of emotional intelligence. Third, emotional intelligence involves emotional knowledge and memory. Knowledge of normative emotional reactions (Gilbert et al., 2009) and the ability to learn from emotional experience (Nielsen, Knutson, \& Carstensen, 2008; Riis et al., 2005; Walsh \& Ayton, 2009; Wilson, Meyer, \& Gilbert, 2001) are instrumental for improving affective forecasting skills.

Despite these suggestive findings, only one published study (Dunn et al., 2007) directly examined the association between emotional intelligence and affective forecasting. They found that one aspect of emotional intelligence, emotional management, was associated with forecasting accuracy; however, observed effects varied considerably ( $r=-.21$ to .59 ) across measures and studies. Further, there are widespread concerns that the predictive validity of emotional intelligence comes merely from its overlap with traditional, cognitive intelligence (Mayer Salovey, \& Caruso, 2008), and no attempt was made to control for the effects of cognitive functioning in that study. Beyond examining whether emotional intelligence is associated with affective forecasting accuracy (Study 1), we also drew upon the existing emotional intelligence literature to guide theoretically driven hypotheses about how affective forecasting skills change with experience (Study 2).

\section{Emotional Intelligence as a Guide to Theoretically Driven Hypotheses}

We hypothesized that, in addition to conferring immediate advantages, emotional intelligence would facilitate experience- dependent improvement in affective forecasting, with the relationship explained by memory processes. People often rely on their memory of similar prior emotional experiences when making affective forecasts (Meyvis, Ratner, \& Levav, 2010; Wilson et al., 2001), though the accuracy and potential value of emotional memories remains an open question. Some studies show that incremental improvement in forecasting accuracy over time is possible with experience (Nielsen et al., 2008; Riis et al., 2005; Walsh \& Ayton, 2009; Wilson et al., 2001), suggesting a potential role for learning and memory. On the other hand, recollected emotional information can depend on heuristic processes (Robinson \& Clore, 2002), which potentially limit its benefit to affective forecasting (Meyvis et al., 2010; Morewedge, Gilbert, \& Wilson, 2005). Thus, although memory of similar emotional experiences is relevant to affective forecasting, the quality of emotional memories may vary substantially across individuals.

Recent theoretical developments (MacCann et al., 2003; Mayer, Salovey, \& Caruso, 2008) have emphasized that emotional intelligence could play a key role in episodic memory for emotional events and learning. In particular, emotional intelligence is associated with crystallized intelligence, autobiographical memory, and the ability to learn new emotional competencies (Aguirre, Sergi, \& Levy, 2008; Boyatzis, Stubbs, \& Taylor, 2002; MacCann, 2010; MacCann et al., 2003; Mikolajczak, Roy, Verstrynge, \& Luminet, 2009). Furthermore, of the broad range of emotional intelligence measures, those that assess acquired emotional knowledge are more strongly associated with psychosocial outcomes (Chapman \& Hayslip, 2006; Mayer Salovey, \& Caruso, 2008; Roberts et al., 2001). Taken together, these findings suggest that emotional intelligence confers advantages in knowledge acquisition and memory, which may facilitate experience-dependent improvement in affective forecasting over time.

\section{Present Investigation}

The present investigation involved two studies examining individual differences in affective forecasting. Study 1 examined the association between emotional intelligence and affective forecasting. After linking emotional intelligence to forecasting accuracy, Study 2 drew upon theoretically driven hypotheses to test whether emotional intelligence was associated with improvement in affective forecasting with experience, and whether observed improvements were explained by basic memory processes, such as the encoding and consolidation of emotional reactions. Findings were expected to show that emotional intelligence is associated with individual differences in affective forecasting and experiencedependent improvements in affective forecasting skills over time.

\section{Study 1: Emotional Intelligence and Affective Forecasting}

Although we are aware of no published meta-analyses, affective forecasting has been examined in the context of over 50 different emotional stimuli and events (e.g., elections, football games, money, and food). At this point in the history of affective forecasting research, no single task or paradigm can be viewed as typical or as a "gold-standard." In the present research, we examined affective forecasting for emotionally evocative pictures. There is a rich history of using pictures in basic emotion research 
(see Robinson \& Clore, 2002; Urry, 2010), including studies relevant to affective forecasting - even though they were not conceptualized as such. For example, in one study (Robinson \& Clore, 2001), participants reported hypothetical emotional reactions to emotionally evocative pictures, based on brief narratives, and then reported real-time reactions upon viewing the pictures. As noted elsewhere (Dunn et al., 2007), affective forecasting studies have typically focused on a single event or stimulus, limiting measurement reliability. We assessed affective forecasting by aggregating across multiple pictures, and this is the first known investigation to report on the reliability of participants' affective forecasting across multiple observations.

\section{Method}

Participants. Undergraduates $(n=81)$ from a large public university in the Midwestern United States participated in the study. They were ages 18 to $35(M=19.2, S D=2.2)$, and mainly female $(62 \%)$ and White $(95 \%)$.

Procedures. Study procedures are summarized in Figure 1. All procedures were administered online via SurveyMonkey.com; reminders were sent via e-mail. Participants rated predicted and actual reactions to the 10 emotionally evocative pictures using a nine-point rating scale, ranging from unpleasant to pleasant. The instructions for predicted reactions stated, "Each item below describes what a particular picture looks like. Attempt to predict how you would feel when viewing each picture, using the nine-point scale." Next, participants read brief written descriptions of each picture (e.g., "A palm tree leaning out over the ocean toward the sun as it sets" and "Police officers with nightsticks raised getting ready to beat a homeless man on the ground"), and rated their predicted reactions to each. Then, 8-10 weeks later, participants rated actual reactions to each picture, viewed in random order, and completed other measures. The instructions for actual reactions were presented below each picture and stated, "How does this picture make you feel?" Pictures were approximately 415 pixels by 396 pixels, with half pleasant; half unpleasant. All pictures in Studies 1 and 2 were obtained from free stock-photo galleries and were piloted previously to avoid ceiling/floor effects. Examples include a cemetery, a woman with a black eye, moldy bread, a sand castle, children sledding, and a family wedding photo. On average, descriptions were 12.0 words $(S D=2.7)$ and had a FleschKincaid Grade Level of $6.8(S D=2.3)$.

Measures. Following prior research, we measured emotional intelligence using self-report surveys and performance-based tests (MacCann et al., 2003; Roberts et al., 2001). As shown in Table 1, all of the emotional intelligence measures used in this investigation yielded reliable scores ( $\alpha=.77$ to .93 ) and demonstrated construct validity, as indicated by convergent and discriminant correlations (Cronbach \& Meehl, 1955).

Emotional intelligence performance-based tests. The 46item Interpersonal Judgment Inventory (IJI; $\alpha=.80$; Christiansen, Wolcott-Burnam, Janovics, Burns, \& Quirk, 2005) measures knowledge of individual differences in personality and emotional reactivity using varying multiple-choice formats. For example, participants are asked to identify which of several situations is most characteristic of "empathy," or to match adjectives to related traits (e.g., "touchy" is related to trait "emotional stability"). Scores on the IJI are correlated with cognitive intelligence as well as the accuracy of judgments about other people's personality, emotions, and psychopathology symptoms (Christiansen et al., 2005). A second test, the Judgment of Emotions Test (JET; $\alpha=$ .81) was designed by our lab to be similar to the IJI, but with a greater focus on emotional knowledge than personality. JET items were based on documented research findings (drawn from reviews, such as Deneve \& Cooper, 1998; Meyer et al., 2001) to enhance objectivity. The scale consists of 40 items, asking participants whether a variety of factors (e.g., education, introversion) are related to higher or lower levels of happiness and other emotions. In pilot testing, scores on the JET were found to correlate with the scores on the IJI, Self-Rated Emotional Intelligence Scale (SREIS; Brackett et al., 2006), and Trait Emotional Intelligence Questionnaire-Short Form (TEIQue-SF; Petrides \& Furnham, 2006), and JET scores demonstrated adequate reliability and construct validity in the present studies (see Table 1).

Emotional intelligence self-report surveys. Participants completed three self-report surveys of emotional intelligence: the SREIS (Brackett et al., 2006), the TEIQue-SF (Petrides \& Furnham, 2006), and the Survey of Emotional Intelligence (SEI; Tett, Wang, Gribler, \& Martinez, 1997). The 19-item SREIS $(\alpha=.83)$ assesses five dimensions of perceived emotional intelligence: Per-
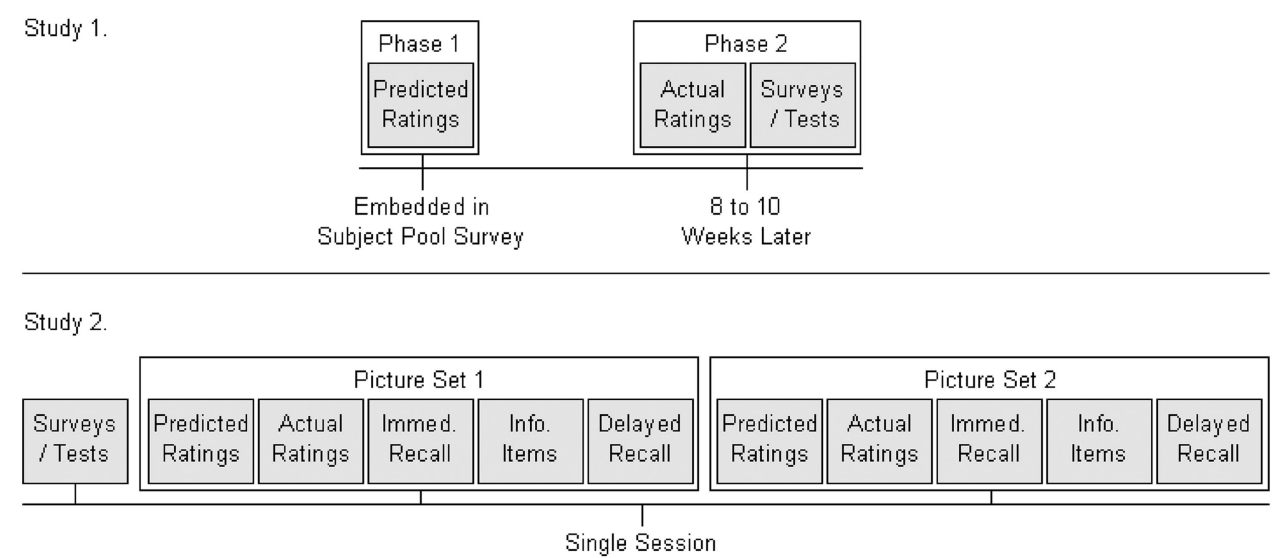

Figure 1. Overview of procedures for affective forecasting studies. 
Table 1

Correlations Among Emotional Intelligence (EI) Measures and Cognitive Indicators (Averaged Across Studies 1 and 2)

\begin{tabular}{|c|c|c|c|c|c|c|c|c|c|c|}
\hline Measure $^{a}$ & 1 & 2 & 3 & 4 & 5 & 6 & 7 & 8 & 9 & 10 \\
\hline \multicolumn{11}{|l|}{ Performance EI } \\
\hline 1. JET & $(.81)$ & & & & & & & & & \\
\hline 2. IJI & .38 & $(.80)$ & & & & & & & & \\
\hline 3. $\mathrm{STEU}^{\mathrm{b}}$ & .59 & .56 & $(.77)$ & & & & & & & \\
\hline \multicolumn{11}{|l|}{ Self-Report EI } \\
\hline 4. SREIS & .28 & .23 & .28 & $(.83)$ & & & & & & \\
\hline 5. TEIQue-SF & .34 & .23 & .36 & .72 & $(.92)$ & & & & & \\
\hline 6. SEI & .26 & .24 & .28 & .70 & .79 & $(.93)$ & & & & \\
\hline \multicolumn{11}{|l|}{ Cognition } \\
\hline 7. College GPA & .13 & .12 & .10 & .16 & .12 & .17 & - & & & \\
\hline 8. VML & .36 & .50 & .55 & .18 & .16 & .19 & .13 & $(.68)$ & & \\
\hline 9. ACT Score & .23 & .39 & .40 & .16 & .16 & .15 & .26 & .54 & - & \\
\hline 10. Information & .21 & .31 & .33 & .17 & .13 & .15 & .10 & .47 & .44 & $(.80)$ \\
\hline
\end{tabular}

Note. $\quad N=511$. Cronbach's alpha values are indicated parenthetically. JET = Judgment of Emotions Test; IJI = Interpersonal Judgment Inventory; STEU = Situational Test of Emotional Understanding; SREIS = Self-Rated Emotional Intelligence Scale; TEIQue-SF = Trait Emotional Intelligence Questionnaire-Short Form; SEI = Survey of Emotional Intelligence; VML = Verbal-Mathematical-Logical Test; Information = Knowledge of general information, similar to WAIS-IV Information subtest.

${ }^{a}$ All correlations are statistically significant at the $p<.05$ level. ${ }^{\mathrm{b}}$ Study 2 only.

ceiving emotions, use of emotions, understanding emotions, managing emotions (self), and managing emotions (other). Participants rated themselves on items, such as "My quick impressions of what other people are feeling are usually wrong" (reverse coded, perceiving emotions) and "I know the strategies to make or improve other people's moods" (managing emotions, other). Additionally, the 30-item TEIQue-SF ( $\alpha=.92)$ was used to assess four dimensions of perceived emotional intelligence: Well-being, emotionality, sociability, and self-control. Participants responded to items, such as "On the whole, I am pleased with my life" (well-being) and "Expressing my emotions with words is not a problem for me" (emotionality). Finally, participants completed the 150-item SEI $(\alpha=.93)$, which examines 12 dimensions of perceived emotional intelligence: Recognition (self), regulation (self), recognition (others), regulation (others), nonverbal expression, empathy, intuition, creative thinking, mood-redirected attention, motivating emotions, delay of gratification, and emotional appraisal. Participants rated items such as, "If a good friend were to return from a long trip, I would feel more happy than thankful" (emotional appraisal) and "I am bothered by the problems of people I don't know" (empathy).

Cognitive functioning. Four indicators of cognitive functioning were recorded for the purposes of covariate analyses. Participants self-reported their American Collegiate Test (ACT) score and college GPA. They also completed a brief test of information $(\alpha=.80)$, which consisted of 26 items testing knowledge of general facts (e.g., "Name all 7 continents" or "What human body part produces insulin?"); the test was modeled after the Wechsler Adult Intelligence Scale-IV Information subtest (Wechsler, 2008). Finally, participants completed the 20-item Verbal-MathematicalLogical Test (VML; $\alpha=.68$; Hoerger, Ketterer, Triemstra, Stone, \& Poinsett, 2006), a multiple-choice test of vocabulary, synonyms, arithmetic, geometry, logical reasoning, and visual-spatial problem solving, previously shown to correlate with the ACT.

Statistical analyses. Principal axis factoring was used to provide summary indicators of performance-based emotional intelligence (based on the JET and IJI), self-report emotional intelligence (based on the SREIS, TEIQue-SF, and SEI), and cognitive functioning (based on GPA, VML, ACT, and Information).
For each of the 10 pictures, prediction-error scores were calculated as the absolute deviation between predicted and actual reactions (Dunn et al., 2007). These error scores were then reverse coded to indicate prediction accuracy, and prediction-accuracy scores were summed across pictures to provide a composite indicator $(\alpha=.71)$. We then examined whether individual difference constructs were associated with prediction accuracy, and whether emotional-intelligence measures accounted for incremental variance in prediction accuracy, upon controlling for cognitive functioning. Post hoc analyses tested for alternative explanations by examining findings separately for errors in the overprediction and underprediction of the intensity of reactions (see Quoidbach \& Dunn, 2010).

\section{Results and Discussion}

Descriptive overview. Across the 10 pictures, the average correlation between predicted and actual reactions was $r=.54$, $p<.001$, and the average discrepancy between predicted and actual ratings was $M=1.05(S D=0.37)$ points on the nine-point scale, which was significant, $d=2.84, t(80)=25.54, p<.001$. For pleasant pictures, predicted ratings were $M=7.41(S D=$ $1.09)$ and actual ratings were $M=7.57(S D=0.86)$. For unpleasant pictures, predicted reaction ratings were $M=1.98(S D=1.05)$ and actual ratings were $M=2.03(S D=0.87)$. A 2 (valence: pleasant vs. unpleasant pictures) $\times 2$ (type: predicted vs. actual ratings) repeated-measures ANOVA indicated that, as intended, pleasant pictures received higher ratings than unpleasant pictures, $F(1,80)=939.50, p<.001$. Predicted ratings were marginally lower than actual ratings, $F(1,80)=3.39, p=.07$. The valence by rating-type interaction was nonsignificant, $F(1,80)=0.62, p=$ .43 , indicating that predictions were not biased uniformly toward overestimating the intensity of future reactions. In fact, $51 \%$ of errors involved overestimating the intensity of actual reactions; $49 \%$ underestimating. Adding individual-difference constructs (performance-based emotional intelligence, self-report emotional intelligence, and cognitive functioning) to the analysis (ANCOVA) did not produce significant interaction effects $(p s>.27)$, mitigat- 
ing the likelihood of potential alternative explanations of subsequent findings. In summary, participants made prediction errors that involved a mix of overestimating and underestimating emotional reactions; next, we examined whether emotional intelligence was associated with accuracy.

Individual differences in affective forecasting accuracy. Individual-differences variables that were significantly correlated with prediction accuracy are shown in Table 2. Three emotional intelligence measures accounted for incremental variance in prediction accuracy when controlling for cognitive functioning: TEIQue-SF well-being, SREIS perceiving emotions, and JET. Results supported our hypothesis that emotional intelligence is associated with greater prediction accuracy. Next, we tested whether emotional intelligence was associated with changes in affective forecasting skills over time.

\section{Study 2: Emotional Intelligence and Improvement in Affective Forecasting Through Experience}

Study 2 was designed to test whether emotional intelligence was associated with improvement in affective forecasting skills as a result of experience, and whether that relationship was explained by memory processes. Although the importance of memory in the development of emotional skills has been hypothesized (MacCann et al., 2003; Mayer Salovey, \& Caruso, 2008), specific memory processes have not been examined. Autobiographical episodic memory can be broken down into constituent processes, including encoding and consolidation (for a review of memory systems and assessment strategies, see Kolb \& Whishaw, 2008). The first stage of memory is encoding, or the perceptual and cognitive process

Table 2

Association Between Emotional Intelligence (EI) and Affective Forecasting Accuracy, Upon Controlling for Cognitive Functioning (Study 1)

\begin{tabular}{ccc}
\hline & \multicolumn{2}{c}{ Prediction accuracy } \\
\cline { 2 - 3 } Measure & $r$ & $\beta$ \\
\hline Performance EI & $.43^{* * *}$ & $.42^{* * *}$ \\
JET & $.42^{* * *}$ & $.38^{* * *}$ \\
IJI & $.29^{* *}$ & .21 \\
Self-Report EI & $.24^{*}$ & .17 \\
SREIS & $.22^{*}$ & .15 \\
Perceiving Emotions & $.38^{* * *}$ & $.33^{* *}$ \\
Managing Emotions (other) & $.22^{*}$ & .18 \\
TEIQue-SF & .21 & .16 \\
Well-being & $.30^{* *}$ & $.27^{* *}$ \\
Emotionality & $.25^{*}$ & .20 \\
SEI & $.22^{*}$ & .14 \\
Emotional Appraisal & $.27^{*}$ & .19 \\
Nonverbal Expression & $.22^{*}$ & .21 \\
Cognitive Functioning & $.24^{*}$ & - \\
College GPA & $.27^{*}$ & - \\
VML & $.24^{*}$ & - \\
\hline
\end{tabular}

Note. $n=81$. $\beta$ s control for cognitive functioning. JET $=$ Judgment of Emotions Test; IJI = Interpersonal Judgment Inventory; SREIS = SelfRated Emotional Intelligence Scale; TEIQue-SF = Trait Emotional Intelligence Questionnaire-Short Form; SEI = Survey of Emotional Intelligence; $\mathrm{VML}=$ Verbal-Mathematical-Logical Test.

${ }^{*} p<.05 .{ }^{* * *} p<.01 .^{* * * *} p<.001$. involved in transforming stimuli into meaningful representations. Stimuli are perceived, organized into bits of data, and stored in meaningful units. Typically, encoding is measured by examining immediate memory for information and events. A next stage of memory is consolidation, or the process of retaining encoded units. Consolidation involves stabilizing or strengthening memory representations as neural pathways are repeatedly transversed. Typically, consolidation is measured by examining delayed memory for information and events, while controlling for initial memory. Based on the premise that emotional intelligence confers advantages in the ability to acquire and benefit from knowledge gained through emotional experience, facilitating improved affective forecasting over time (MacCann et al., 2003; Mayer Salovey, \& Caruso, 2008), we hypothesized that both encoding and consolidation would play a role in explaining the association between emotional intelligence and forecasting improvement.

\section{Method}

Participants. A new sample of undergraduates $(n=430)$ from the same university completed a single-session, affectiveforecasting study conducted online. Participants were ages 18 to 47 $(M=19.7, S D=3.2)$, and mainly female $(71 \%)$ and White $(94 \%)$.

Procedures. Participants completed six emotional intelligence measures and the VML test (Hoerger et al., 2006), followed by two affective forecasting tasks involving emotional pictures (see Figure 1). Each participant made four sets of emotion ratings (predicted, actual, immediately recollected, and delayed recollected) for each of two sequential forecasting tasks, yielding eight total sets of ratings. Between immediate and delayed recall, participants answered questions from the 26-item Information test (see Study 1) to create a time lag of about five minutes.

Participants predicted their reactions to each of 20 pictures based on concise narrative descriptions of the pictures, which were listed in random order. Immediately thereafter, they viewed the set of 20 pictures, with each picture presented in random order, and rated their actual reactions to each picture. The average time between predicted and actual ratings varied randomly with a mean latency of approximately three minutes. Procedures for recollected reactions were similar to those used to obtain predicted ratings. Specifically, instructions stated, "Please attempt to recall how you felt when you viewed each of the pictures described below, using the nine-point scale." Participants then read the descriptions of the pictures and rated their recollected reactions to each. The same procedures were then repeated with a second set of 20 new pictures. Any improvement on the second set was due to incidental learning, as participants were not provided with any feedback on their performance.

All emotional reactions were rated on a nine-point scale, ranging from unpleasant to pleasant, and each picture set included 20 pictures. Pictures were approximately 460 pixels by 428 pixels. On average, descriptions were 9.2 words $(S D=3.5)$ and had a Flesch-Kincaid Grade Level of $7.3(S D=4.3)$.

Measures. As in Study 1, participants completed the IJI (Christiansen et al., 2005), JET (from Study 1), SREIS (Brackett et al., 2006), TEIQue-SF (Petrides \& Furnham, 2006), SEI (Tett et al., 1997), VML (Hoerger et al., 2006), and Information test (from Study 1), plus provided their ACT score and college GPA. A third performance-based emotional intelligence test was also added: The 
42-item Situational Test of Emotional Understanding (STEU; $\alpha=$ .77; MacCann \& Roberts, 2008). The STEU includes multiplechoice items, such as, "By their own actions, a person reaches a goal they wanted to reach. The person is most likely to feel? (a) Joy, (b) hope, (c) relief, (d) pride, (e) surprise." STEU items are scored using criteria based on the developers' theoretical model of emotion (see MacCann \& Roberts, 2008). The construct validity of the STEU is supported by studies showing its convergent validity with other performance-based emotional intelligence tests as well as measures of crystallized intelligence (Austin, 2010; MacCann, 2010).

Statistical analyses. Principal axis factoring was used to provide summary indicators of performance-based emotional intelligence (based on the JET, IJI, and STEU), self-report emotional intelligence (based on the SREIS, TEIQue-SF, and SEI), and cognitive functioning (based on GPA, VML, ACT, and the information test)

Seven outcome variables were derived from the eight sets of emotion ratings: Prediction accuracy, encoding accuracy, and consolidation accuracy on the first picture set, improvement in each of these three domains on the second picture set, and a composite indicator of total improvement on the second set of pictures. Prediction accuracy was calculated using the same procedures as Study 1 (see also Dunn et al., 2007): The reverse-coded, absolute deviation between predicted and actual emotion ratings were averaged across 20 pictures. Encoding accuracy was computed using analogous procedures, but instead used the deviation between actual ratings and immediately recollected ratings. Consolidation accuracy was conceptualized as accuracy in delayed recollection ratings, controlling for accuracy in immediately recollected ratings (Kolb \& Whishaw, 2008). Thus, we computed accuracy scored for delayed recollected ratings (using the absolute deviation procedures), and then used regression to control for the accuracy of immediately recollected reactions. This procedure has advantages over using simple difference scores to control for performance in immediate recollection (Cohen, Cohen, West, \& Aiken, 2003; Hand \& Taylor, 1987), including producing an indicator of consolidation accuracy that is orthogonal to encoding accuracy. For the second picture set, we computed improvements in prediction accuracy, encoding accuracy, and consolidation accuracy by controlling for performance on the first picture set (Cohen et al., 2003;
Hand \& Taylor, 1987). For example, improvement in consolidation was computed as consolidation accuracy on the second picture set, using regression to control for consolidation accuracy on the first picture set. A composite indicator of total improvement was calculated by summing across improvement scores for prediction, encoding, and consolidation. For both picture sets, accuracy scores for predicted and recollected ratings demonstrated good reliability (average $\alpha=.88$; see Table 3).

Our analyses examined descriptive statistics, correlations between individual-differences constructs and performance on the affective forecasting tasks, and the incremental validity of emotional intelligence measures over cognitive functioning in accounting for performance on the affective forecasting tasks. Finally, mediation analyses using bias-corrected bootstrapping (Preacher \& Hayes, 2008; 10,000 resamples with a 95\% confidence interval) were implemented to determine whether the association between emotional intelligence and improvement in affective forecasting was mediated by memory processes.

\section{Results and Discussion}

Descriptive overview. Ratings for actual emotional reactions to the pictures were significantly correlated with predicted ratings $(r=.60, p<.001)$, immediately recollected ratings $(r=.81, p<$ $.001)$, and delayed recollected ratings $(r=.80, p<.001)$. On the first picture set, actual reactions differed in absolute magnitude from predicted reactions by $M=0.70(S D=0.59)$ points on the nine-point rating scale $(d=1.19, t(429)=24.60, p<.001)$; from immediately recollected reactions by $M=0.33(S D=0.50)$ points $(d=0.66, t(429)=13.64, p<.001)$; and from delayed recollected reactions by $M=0.35(S D=0.53)$ points $(d=0.66, t(429)=$ 13.74, $p<.001)$. On the second picture set, actual reactions differed in absolute magnitude from predicted reactions by $M=$ $0.64(S D=0.59)$ points on the nine-point rating scale $(d=1.09$, $t(429)=22.57, p<.001)$; from immediately recollected reactions by $M=0.25(S D=0.49)$ points $(d=0.51, t(429)=10.57, p<$ $.001)$; and from delayed recollected reactions by $M=0.26(S D=$ $0.47)$ points $(d=0.56, t(429)=11.52, p<.001)$. There was no significant trend toward overestimating the pleasantness of reactions to pleasant pictures or the unpleasantness of unpleasant pictures (average $d=0.06, t(429)=0.63, p=.53$ ).

Table 3

Correlations Across Accuracy in Prediction, Immediate Recollection, and Delayed Recollection (Study 2)

\begin{tabular}{|c|c|c|c|c|c|c|}
\hline Accuracy score ${ }^{a}$ & 1 & 2 & 3 & 4 & 5 & 6 \\
\hline \multicolumn{7}{|l|}{ Picture Set 1} \\
\hline 1. Prediction & $(.86)$ & & & & & \\
\hline 2. Immediate Recollection & .72 & $(.90)$ & & & & \\
\hline 3. Delayed Recollection & .73 & .85 & $(.91)$ & & & \\
\hline \multicolumn{7}{|l|}{ Picture Set 2} \\
\hline 4. Prediction & .63 & .65 & .73 & $(.83)$ & & \\
\hline 5. Immediate Recollection & .63 & .82 & .78 & .69 & $(.91)$ & \\
\hline 6. Delayed Recollection & .64 & .83 & .81 & .72 & .83 & $(.90)$ \\
\hline
\end{tabular}

Note. $n=430$. Accuracy scores computed based on the absolute deviation from actual emotional reactions. In our subsequent analyses, encoding skills were assessed based on immediate recollection. Consolidation skills were assessed based on delayed recollection scores, controlling for immediate recollection scores.

${ }^{a}$ All correlations are statistically significant at the $p<.001$ level. 
Specifically, 53\% of errors involved overestimation and $47 \%$ involved underestimation. Correlations across accuracy scores are shown in Table 3.

Individual differences in affective forecasting accuracy. Core analyses examined individual differences in seven dependent variables related to affective forecasting (see Table 4). As hypothesized, performance-based emotional intelligence tests, self-report surveys, and cognitive functioning were associated with performance on the initial affective forecasting task, as well as improvement on the second set of forecasting tasks.

Incremental validity. Table 5 shows that performance-based emotional intelligence accounted for incremental variance in prediction accuracy, encoding accuracy, consolidation accuracy, and total improvement, when controlling for both cognitive functioning and self-report emotional intelligence. In contrast, self-report emotional intelligence explained incremental variance in prediction, encoding, and consolidation accuracy, but not improvement, when controlling for cognitive functioning, and only explained incremental variance in prediction accuracy when controlling for both cognitive functioning and performance-based emotional intelligence.
Mediation analyses. Finally, mediation analyses were used to examine the extent to which basic memory processes (encoding and consolidation) explained the association between emotional intelligence and task improvement (see Figure 2). Using the biascorrected bootstrapping method (Preacher \& Hayes, 2008), the total indirect effect was significant, $t(429)=2.22, p=.03(a b=$ $.28, S E=.13, \mathrm{CI}=.03$ to .54$)$. Encoding and consolidation of emotional memories explained $72 \%$ of the association between emotional intelligence and task improvement (i.e., a beta of .25 without controlling for encoding/consolidation, changing to .07 after controlling for these, leading to a $(.25-.07) / .25=.72$ reduction in coefficient representing the association of EI and task improvement). In terms of specific indirect effects, the pathway mediated by consolidation was statistically significant, $t(429)=$ $2.48, p=.01(a b=.14, S E=.05, \mathrm{CI}=.05$ to .27$)$, whereas the pathway mediated by encoding did not meet significance, $t(429)=$ $1.47, p=.14(a b=.15, S E=.10, \mathrm{CI}=-.06$ to .36$)$. Thus, in partial support of our hypotheses, memory processes explained $72 \%$ of the relationship between emotional intelligence and improved affective forecasting, but consolidation was a more salient mediator than encoding.

Table 4

Emotional Intelligence (EI) and Cognitive Functioning Correlate With Accuracy in Predicting, Encoding, and Consolidating Emotional Reactions on Picture Set 1; Improved Performance on Picture Set 2 (Study 2)

\begin{tabular}{|c|c|c|c|c|c|c|c|}
\hline \multirow[b]{2}{*}{ Measure } & \multicolumn{3}{|c|}{ Picture set 1} & \multicolumn{4}{|c|}{ Picture set 2} \\
\hline & $\begin{array}{c}\text { Prediction } \\
\text { accuracy }\end{array}$ & $\begin{array}{l}\text { Encoding } \\
\text { accuracy }\end{array}$ & $\begin{array}{c}\text { Consolidation } \\
\text { accuracy }\end{array}$ & $\begin{array}{l}\text { Improved } \\
\text { prediction }\end{array}$ & $\begin{array}{l}\text { Improved } \\
\text { encoding }\end{array}$ & $\begin{array}{c}\text { Improved } \\
\text { consolidation }\end{array}$ & $\begin{array}{c}\text { Total } \\
\text { improvement }\end{array}$ \\
\hline Performance EI Factor & $.44^{* * * *}$ & $.41^{* * * *}$ & $.25^{* * * *}$ & $.11^{*}$ & $.16^{* * * *}$ & $.19^{* * * *}$ & $.25^{* * * * *}$ \\
\hline JET & $.57^{* * * *}$ & $.47^{* * * *}$ & $.27^{\text {**** }}$ & $.10^{*}$ & $.14^{\text {*** }}$ & $.11^{*}$ & $.19^{\text {**** }}$ \\
\hline STEU & $.40^{* * * * *}$ & $.38^{* * * *}$ & $.24^{* * * * *}$ & $.10^{*}$ & $.16^{\text {***** }}$ & $.19^{* * * *}$ & $.24^{\text {***** }}$ \\
\hline IJI & $.22^{\text {****** }}$ & $.23^{* * * * *}$ & $.12^{*}$ & .09 & .06 & $.10^{*}$ & $.13^{* * *}$ \\
\hline Self-Report EI Factor & $.30^{\text {***** }}$ & $.21^{* * * * *}$ & $.13^{\text {*** }}$ & .02 & .09 & $.11^{*}$ & $.11^{*}$ \\
\hline SREIS & $.25^{* * * * *}$ & $.17^{* * * * *}$ & .07 & -.01 & .07 & .06 & .06 \\
\hline Managing Emotions (other) & $.27^{* * * *}$ & $.19^{* * * * *}$ & .08 & .00 & .08 & .04 & .06 \\
\hline Perceiving Emotions & $.24^{* * * * *}$ & $.17^{* * * * *}$ & $.10^{*}$ & -.03 & $.12^{*}$ & .01 & .06 \\
\hline Managing Emotions (self) & $.16^{* * * *}$ & .09 & .02 & .04 & .04 & .07 & .08 \\
\hline Understanding Emotions & $.13^{* *}$ & .07 & .01 & -.01 & -.01 & .05 & .01 \\
\hline TEIQue-SF & $.31^{* * * * *}$ & $.22^{* * * *}$ & $.13^{* * *}$ & .04 & .09 & $.14^{* *}$ & $.14^{* *}$ \\
\hline Emotionality & $.29^{* * * *}$ & $.20^{* * * * *}$ & $.10^{*}$ & -.01 & .07 & $.13^{* *}$ & $.10^{*}$ \\
\hline Well-being & $27^{* * * * *}$ & $.22^{* * * * *}$ & .09 & -.02 & .07 & $.15^{* *}$ & $10^{*}$ \\
\hline Sociability & $.21^{* * * *}$ & $.18^{* * * *}$ & .09 & .10 & $.11^{*}$ & .09 & .08 \\
\hline Self-control & $20^{* * * * *}$ & $.13^{* * *}$ & $.14^{* * *}$ & .04 & .04 & .07 & $.16^{* * * *}$ \\
\hline SEI & $.25^{\text {****** }}$ & $.16^{* * * * *}$ & $.13^{* * *}$ & .00 & .09 & .07 & .09 \\
\hline Emotional Appraisal & $.30^{* * * * *}$ & $.25^{* * * * *}$ & $.13^{* *}$ & .00 & .07 & .08 & .08 \\
\hline Empathy & $.25^{* * * *}$ & $.13^{* * *}$ & $.13^{* *}$ & -.01 & $.11^{*}$ & .06 & .09 \\
\hline Recognition (others) & $.22^{* * * * *}$ & $.17^{* * * *}$ & $.11^{*}$ & .04 & .08 & .05 & .09 \\
\hline Regulation (others) & $.21^{* * * * *}$ & $.13^{* * *}$ & $.11^{*}$ & .00 & .06 & .01 & .04 \\
\hline Motivating Emotions & $.20^{* * * *}$ & $.15^{* * *}$ & .08 & .06 & .08 & .05 & $.11^{*}$ \\
\hline Mood Redirected Attention & $.15^{* * *}$ & $.14^{* * *}$ & .05 & -.02 & .08 & .02 & $.14^{* * *}$ \\
\hline Nonverbal Expression & $.12 *$ & $.10^{*}$ & .06 & -.05 & .01 & .04 & -.01 \\
\hline Recognition (self) & $.11^{*}$ & .05 & .04 & -.06 & .03 & .08 & .02 \\
\hline Cognitive Functioning Factor & $.17^{\text {***** }}$ & $.11^{*}$ & $.14^{* *}$ & $.13^{* *}$ & $.16^{* * * * *}$ & .09 & $.21^{\text {****** }}$ \\
\hline Information & $.14^{* * *}$ & $.17^{* * * * *}$ & .03 & $.17^{* * * *}$ & $.14^{* * *}$ & .08 & $.22^{* * * * *}$ \\
\hline VML & $.13^{* * *}$ & $.14^{* * *}$ & $.10^{*}$ & .07 & .09 & .09 & $.14^{* * *}$ \\
\hline ACT Score & $.12^{*}$ & .09 & .09 & .09 & .08 & $.10^{*}$ & $.15^{\text {*** }}$ \\
\hline College GPA & .07 & -.01 & $.12^{*}$ & $.14^{* *}$ & $.11^{*}$ & .04 & $.16^{* * * * * *}$ \\
\hline
\end{tabular}

Note. $\quad n=430$. JET $=$ Judgment of Emotions Test; IJI = Interpersonal Judgment Inventory; STEU $=$ Situational Test of Emotional Understanding; SREIS = Self-Rated Emotional Intelligence Scale; TEIQue-SF = Trait Emotional Intelligence Questionnaire-Short Form; SEI = Survey of Emotional Intelligence; VML = Verbal-Mathematical-Logical Test; Information $=$ Knowledge of general information, similar to WAIS-IV Information subtest. ${ }^{*} p<.05 .{ }^{* * *} p<.01 .{ }^{* * * *} p<.001$. 
Table 5

Emotional Intelligence (EI) Accounts for Incremental Variance $\left(\Delta R^{2}\right)$ in Affective Forecasting Accuracy and Improvement, Over Cognitive Functioning (CF) (Study 2)

\begin{tabular}{lcccc}
\hline \multicolumn{1}{c}{ Hierarchical regression } & $\begin{array}{c}\text { Prediction } \\
\text { accuracy }\end{array}$ & $\begin{array}{c}\text { Encoding } \\
\text { accuracy }\end{array}$ & $\begin{array}{c}\text { Consolidation } \\
\text { accuracy }\end{array}$ & $\begin{array}{c}\text { Total } \\
\text { improvement }\end{array}$ \\
\hline $\begin{array}{l}\text { Performance EI } \\
\text { Over CF }\end{array}$ & $.19^{* * * *}$ & $.14^{* * * *}$ & $.06^{* * * *}$ & $.03^{* * * *}$ \\
$\quad \begin{array}{l}\text { Over CF and Self-Report EI } \\
\text { Self-Report EI }\end{array}$ & $.14^{* * *}$ & $.12^{* * *}$ & $.05^{* * *}$ & $.03^{* * *}$ \\
$\quad$ Over CF & $.06^{* * * *}$ & $.02^{* * *}$ & $.02^{* * *}$ & .00 \\
Over CF and Performance EI & $.02^{* * *}$ & .00 & .00 & .00 \\
\hline
\end{tabular}

Note. $n=430 . \Delta \mathrm{R}^{2}$ values shown in table. $\mathrm{CF}$ is based on GPA, VML, ACT, and Information. Performance EI is based on JET, IJI, and STEU. Self-report EI is based on SREIS, TEIQue-SF, and SEI.

${ }^{*} p<.05 .{ }^{* * *} p<.01 .{ }^{* * * *} p<.001$.

\section{General Discussion}

Emotional intelligence was associated with enhanced affective forecasting accuracy, better memory for affective reactions, and improved affective forecasting skills with experience. Effects were robust across studies, measures, and timeframes, even when controlling for an often ignored potential confound, cognitive functioning. This investigation is unique in that it framed prior findings on individual differences in affective forecasting (Emanuel et al., 2010; Gilbert et al., 2009; Hoerger \& Quirk, 2010; Hoerger et al., 2009, 2010; Hoerger, Quirk, Chapman, et al., in press; Quoidbach \& Dunn, 2010; Tomlinson et al., 2010), and demonstrated how the emotional intelligence literature could be used to guide theoretically driven hypotheses.

These findings contribute directly to our understanding of the basic processes underlying individual differences in affective forecasting. Based on prior research (MacCann et al., 2003; Mayer, Salovey, \& Caruso, 2008; Nielsen et al., 2008; Riis et al., 2005; Walsh \& Ayton, 2009; Wilson et al., 2001), we had hypothesized that improvements in affective forecasting would be explained by individual differences in memory of personal emotional reactions to similar situations. Consistent with this hypothesis, we have provided preliminary evidence suggesting that the relationship between emotional intelligence and improvement in affective forecasting is explained by memory processes. Consolidation-the process of retaining previously encoded experiences in memorymay be particularly important for the development of affective forecasting skills.

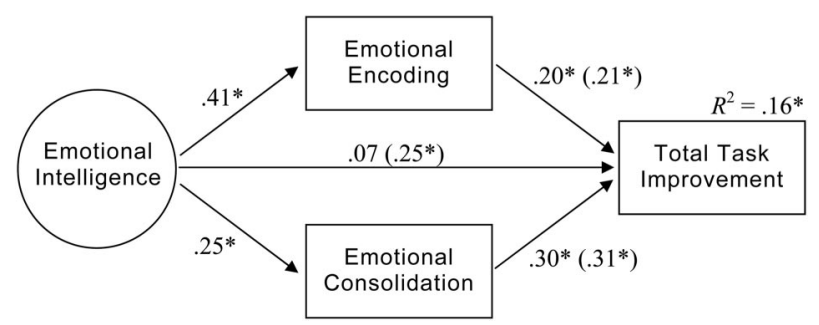

Figure 2. Memory processes explain the association between emotional intelligence and improvement in affective forecasting accuracy over time (Study 2). Parenthetical values are zero-order correlations, and other values are path coefficients. $n=430$. ${ }^{*} p<.05$.
The present investigation also contributes to the generalizability of evidence for discrepancies in affective forecasting. Affective forecasting errors involved both overpredicting and underpredicting the intensity of actual emotional reactions. Prior studies have often reported a tendency to overpredict the intensity of future emotional reactions (e.g., Hoerger et al., 2009; Hoerger \& Quirk, 2010; Wilson et al., 2000), whereas other studies and subsamples have demonstrated a lack of directional bias (e.g., Böhm \& Pfister, 2008; Dunn et al., 2007; Gilbert et al., 1998; Hoerger et al., 2010), and some have reported an underprediction bias (e.g., Lench, Safer, \& Levine, 2011; Norris, Dumville, \& Lacy, 2011). Integrating these findings, it may be that affective forecasting problems occur across a variety of contexts, but systematic biases (e.g., toward overprediction) are more likely to occur in specific situations, such as when participants neglect future coping strategies (Dillard et al., 2010; Gilbert et al., 1998; Hoerger et al., 2009). Similar psychological mechanisms may account for individual differences in affective forecasting accuracy, regardless of the directionality of forecasting errors (Lench et al., 2011).

Findings from the present investigation are qualified by several limitations. Foremost, findings were based on samples primarily composed of young, White adults; generalizability of observed effects to older adults and ethnically diverse participants warrants further attention. Further, any particular emotional stimulus or event has identifiable strengths and weaknesses, and cross-task generalizability warrants attention in future studies. For example, as with any affective forecasting task, our emotional-pictures paradigm may have required some context-dependent skills, such as use of emotional imagery, that are less salient in other affective forecasting contexts. Finally, any direct comparisons among results from Studies 1 and 2 must be tempered by the different timeframes employed.

Nonetheless, study limitations were countered by several strengths. Our affective forecasting tasks were innovative. We used aggregated observations to enhance reliability and a multiphasic forecasting task to address novel questions about memory and task improvement. Additionally, we incorporated recent recommendations calling for the greater study of emotional knowledge acquisition (MacCann \& Roberts, 2008; Mayer, Salovey, \& Caruso, 2008). Further, the large sample size and use of factor scores in Study 2 provided good power. Finally, we tested an explanatory mechanism for individual differences in affective 
forecasting accuracy, rather than resorting to a purely descriptive account.

The present investigation has implications for future directions in applied and basic research. Future applied studies can examine the association between affective forecasting, choice, and decisional satisfaction for applied decisions, including those involving health care, personal finance, and public policy (Dillard et al., 2010; Elwyn et al., 2011; Halpern \& Arnold, 2008; Hoerger et al., 2010; Walsh \& Ayton, 2009). Studies can also examine whether experimental strategies for improving affective forecasts (Hoerger et al., 2010; Wilson et al., 2000) can be adapted to applied decision-making contexts, such as recent efforts to embed information relevant to affective forecasting within existing health decision support interventions (Dillard et al., 2010).

Several basic research questions also warrant further attention. Future studies examining longitudinal improvement in forecasting accuracy are needed to more clearly delineate the role of basic memory processes. For instance, improved forecasting could be tied to memory for emotional events specifically, or linked to higher-order neurocognitive processes, such as general episodic or declarative memory (Tulving \& Schacter, 1990). Next, our findings suggest a strong conceptual overlap between emotional intelligence and affective forecasting. Future factor-analytic studies can test whether forecasting accuracy is better characterized as a specific component of emotional intelligence or a more distinct construct. Finally, developmental influences, such as parental child rearing strategies, have been linked to other aspects of cognitiveemotional reasoning, namely delay of gratification (Hoerger, Quirk, \& Weed, in press). Developmental factors might also be associated with affective forecasting, which could have significant practical implications.

In conclusion, this is the first study of which we are aware that attempts to explain why emotional intelligence is linked to affective forecasting. Our findings emphasize the importance of learning and memory processes in the development of affective forecasting skills. Together with prior studies, the current findings point to the need to conduct basic research to identify causal mechanisms, and encourage an array of potential clinical applications.

\section{References}

Aguirre, F., Sergi, M. J., \& Levy, C. A. (2008). Emotional intelligence and social functioning in persons with schizotypy. Schizophrenia Research, 104, 255-264. doi:10.1016/j.schres.2008.05.007

Austin, E. J. (2010). Measurement of ability emotional intelligence: Results for two new tests. British Journal of Psychology, 101, 563-578. doi:10.1348/000712609X474370

Böhm, G., \& Pfister, H. R. (2008). Anticipated and experienced emotions in environmental risk perception. Judgment and Decision Making, 3, 73-86.

Boyatzis, R. E., Stubbs, E. C., \& Taylor, S. N. (2002). Learning cognitive and emotional intelligence competencies through graduate management education. Academy of Management Learning \& Education, 1, 150-162. doi:10.5465/AMLE.2002.8509345

Brackett, M. A., Rivers, S. E., Shiffman, S., Lerner, N., \& Salovey, P. (2006). Relating emotional abilities to social functioning: A comparison of self-report and performance measures of emotional intelligence. Journal of Personality and Social Psychology, 91, 780-795. doi:10.1037/ 0022-3514.91.4.780

Chapman, B. P., \& Hayslip, B. (2006). Emotional intelligence in young and middle adulthood: Cross-sectional analysis of latent structure and means Psychology and Aging, 21, 411-418. doi:10.1037/0882-7974.21.2.411

Christiansen, N. D., Wolcott-Burnam, S., Janovics, J. E., Burns, G. N., \& Quirk, S. W. (2005). The good judge revisited: Individual differences in the accuracy of personality judgments. Human Performance, 18, 123149. doi:10.1207/s15327043hup1802_2

Cohen, J., Cohen, P., West, S. G., \& Aiken, L. S. (2003). Applied multiple regression/correlation analysis for behavioral sciences (3rd ed.; pp. 568-607). Mahwah, NJ: Erlbaum.

Cronbach, L. J., \& Meehl, P. E. (1955). Construct validity in psychological tests. Psychological Bulletin, 52, 281-302. doi:10.1037/h0040957

DeNeve, K. M., \& Cooper, H. (1998). The happy personality: A metaanalysis of 137 personality traits and subjective well-being. Psychological Bulletin, 124, 197-229. doi:10.1037/0033-2909.124.2.197

Dillard, A. J., Fagerlin, A., Cin, S. D., Zikmund-Fisher, B. J., \& Ubel, P. A. (2010). Narratives that address affective forecasting errors reduce perceived barriers to colorectal cancer screening. Social Science \& Medicine, 71, 45-52. doi:10.1016/j.socscimed.2010.02.038

Dunn, E. W., Brackett, M., Ashton-James, C., Schneiderman, E., \& Salovey, P. (2007). On emotionally intelligent time travel: Individual differences in affective forecasting ability. Personality and Social Psychology Bulletin, 33, 85-93. doi:10.1177/0146167206294201

Dunn, E. W., \& Laham, S. A. (2006). Affective forecasting: A user's guide to emotional time travel. In J. Forgas (Ed.), Affect in social thinking and behavior (pp. 177-196). New York, NY: Psychology Press.

Elwyn, G., Stiel, M., Durand, M. A., \& Boivin, J. (2011). The design of patient decision support interventions: Addressing the theory-practice gap. Journal of Evaluation in Clinical Practice, 17, 565-574. doi: 10.1111/j.1365-2753.2010.01517.x

Emanuel, A. S., Updegraff, J. A., Kalmbach, D. A., \& Ciesl, J. (2010). The role of mindfulness facets in affective forecasting. Personality and Individual Differences, 49, 815-818. doi:10.1016/j.paid.2010.06.012

Fisher, J. E., Sass, S. M., Heller, W., Silton, R. L., Edgar, J. C., Stewart, J. L., \& Miller, G. A. (2010). Time course of processing emotional stimuli as a function of perceived emotional intelligence, anxiety, and depression. Emotion, 10, 486-497. doi:10.1037/a0018691

Gilbert, D. T., Killingsworth, M. A., Eyre, R. E., \& Wilson, T. D. (2009). The surprising power of neighborly advice. Science, 323, 1617-1619. doi:10.1126/science. 1166632

Gilbert, D. T., Pinel, E. C., Wilson, T. D., Blumberg, S. J., \& Wheatley, T. P. (1998). Immune neglect: A source of durability bias in affective forecasting. Journal of Personality and Social Psychology, 75, 617-638. doi:10.1037/0022-3514.75.3.617

Gilbert, D. T., \& Wilson, T. D. (2007). Prospection: Experiencing the future. Science, 317, 1351-1354. doi:10.1126/science.1144161

Halpern, J., \& Arnold, R. M. (2008). Affective forecasting: An unrecognized challenge in making serious health decisions. Journal of General Internal Medicine, 23, 1708-1712. doi:10.1007/s11606-008-0719-5

Hand, D. J., \& Taylor, C. C. (1987). Multivariate analysis of variance and repeated measures: A practical approach for behavioural scientists (pp. 157-166). London, England, United Kingdom: Chapman \& Hall. doi: 10.1007/978-94-009-3143-5_10

Hoerger, M., Ketterer, H., Triemstra, K., Stone, T., \& Poinsett, M. (2006). Verbal-Mathematical-Logical Test (VML). Unpublished test manual, Central Michigan University, Mount Pleasant, MI.

Hoerger, M., \& Quirk, S. W. (2010). Affective forecasting and the Big Five. Personality and Individual Differences, 49, 972-976. doi:10.1016/ j.paid.2010.08.007

Hoerger, M., Quirk, S. W., Chapman, B. P., \& Duberstein, P. R. (in press). Affective forecasting and self-rated symptoms of depression, anxiety, and hypomania: Evidence for a dysphoric forecasting bias. Cognition \& Emotion.

Hoerger, M., Quirk, S. W., Lucas, R. E., \& Carr, T. H. (2009). Immune 
neglect in affective forecasting. Journal of Research in Personality, 43, 91-94. doi:10.1016/j.jrp.2008.10.001

Hoerger, M., Quirk, S. W., Lucas, R. E., \& Carr, T. H. (2010). Cognition determinants of affective forecasting errors. Judgment and Decision Making, 5, 365-373.

Hoerger, M., Quirk, S. W., \& Weed, N. C. (in press). Development and validation of the Delaying Gratification Inventory. Psychological Assessment.

Kolb, B., \& Whishaw, I. (2008). Fundamentals of Human Neuropsychology. New York, NY: Worth.

Lench, H. C., Safer, M. A., \& Levine, L. J. (2011). Focalism and the underestimation of future emotion: When it's worse than imagined. Emotion, 11, 278-285. doi:10.1037/a0022792

Loewenstein, G., \& Lerner, J. S. (2003). The role of affect in decision making. In R. Davidson, H. Goldsmith, \& K. Scherer (Eds.), Handbook of affective science (pp. 619-642). Oxford, England, United Kingdom: Oxford University Press.

MacCann, C. (2010). Further examination of emotional intelligence as a standard intelligence: A latent variable analysis of fluid intelligence, crystallized intelligence, and emotional intelligence. Personality and Individual Differences, 49, 490-496. doi:10.1016/j.paid.2010.05.010

MacCann, C., Matthews, G., Zeidner, M., \& Roberts, R. D. (2003). Psychological assessment of emotional intelligence: A review of selfreport and performance-based testing. The International Journal of Organizational Analysis, 11, 247-274. doi:10.1108/eb028975

MacCann, C., \& Roberts, R. D. (2008). New paradigms for assessing emotional intelligence: Theory and data. Emotion, 8, 540-551. doi: 10.1037/a0012746

Mayer, J. D., Caruso, D. R., \& Salovey, P. (1999). Emotional intelligence meets traditional standards for an intelligence. Intelligence, 27, 267-298. doi:10.1016/S0160-2896(99)00016-1

Mayer, J. D., Roberts, R. D., \& Barsade, S. G. (2008). Human abilities: Emotional intelligence. Annual Review of Psychology, 59, 507-536. doi:10.1146/annurev.psych.59.103006.093646

Mayer, J. D., Salovey, P., \& Caruso, D. (2002). Mayer-Salovey-Caruso Emotional Intelligence Test. Toronto, ON, Canada: Multi-Heath Systems.

Mayer, J. D., Salovey, P., \& Caruso, D. R. (2008). Emotional intelligence: New ability or eclectic traits? American Psychologist, 63, 503-517. doi:10.1037/0003-066X.63.6.503

Mayer, J. D., Salovey, P., Caruso, D. R., \& Sitarenios, G. (2001). Emotional intelligence as a standard intelligence. Emotion, 1, 232-242. doi:10.1037/1528-3542.1.3.232

Mellers, B. (2000). Choice and the relative pleasure of consequences. Psychological Bulletin, 126, 910-924. doi:10.1037/0033-2909 .126.6.910

Meyer, G. J., Finn, S. E., Eyde, L. D., Kay, G. G., Moreland, K. L., Dies, R. R., . . \& Reed, G. M. (2001). Psychological testing and psychological assessment: A review of evidence and issues. American Psychologist, 56, 128-165. doi:10.1037/0003-066X.56.2.128

Meyvis, T., Ratner, R. K., \& Levav, J. (2010). Why don't we learn to accurately forecast feelings? How misremembering our predictions blinds us to past forecasting errors. Journal of Experimental Psychology, 139, 579-589.

Mikolajczak, M., Roy, E., Verstrynge, V., \& Luminet, O. (2009). An exploration of the moderating effect of trait emotional intelligence on memory and attention in neutral and stressful conditions. British Journal of Psychology, 100, 699-715. doi:10.1348/000712608X395522

Morewedge, C. K., Gilbert, D. T., \& Wilson, T. D. (2005). The least likely of times: How remembering the past biases forecasts of the future. Psychological Science, 16, 626-630. doi:10.1111/j.14679280.2005.01585.x
Nielsen, L., Knutson, B., \& Carstensen, L. L. (2008). Affect dynamics, affective forecasting, and aging. Emotion, 8, 318-330. doi:10.1037/ 1528-3542.8.3.318

Norris, C. J., Dumville, A. G., \& Lacy, D. P. (2011). Affective forecasting errors in the 2008 election: Underpredicting happiness. Political Psychology, 32, 235-249. doi:10.1111/j.1467-9221.2010.00818.x

Petrides, K., \& Furnham, A. (2006). The role of trait emotional intelligence in a gender-specific model of organizational variables. Journal of Applied Social Psychology, 36, 552-569. doi:10.1111/j.00219029.2006.00019.x

Preacher, K. J., \& Hayes, A. F. (2008). Asymptotic and resampling strategies for assessing and comparing indirect effects in multiple mediator models. Behavior Research Methods, 40, 879-891. doi:10.3758/ BRM.40.3.879

Quoidbach, J., \& Dunn, E. W. (2010). Personality neglect: The unforeseen impact of personal dispositions on emotional life. Psychological Science, 21, 1783-1786. doi:10.1177/0956797610388816

Riis, J., Loewenstein, G., Baron, J., Jepson, C., Fagerlin, A., \& Ubel, P. A. (2005). Ignorance of hedonic adaptation to hemodialysis: A study using ecological momentary assessment. Journal of Experimental Psychology: General, 134, 3-9. doi:10.1037/0096-3445.134.1.3

Roberts, R., Zeidner, M., \& Matthews, G. (2001). Does emotional intelligence meet traditional standards for an intelligence? Some new data and conclusions. Emotion, 1, 196-231. doi:10.1037/1528-3542.1.3.196

Robinson, M. D., \& Clore, G. L. (2001). Simulation, scenarios, and emotional appraisal: Testing the convergence of real and imagined reactions to emotional stimuli. Personality and Social Psychology Bulletin, 27, 1520-1532. doi:10.1177/01461672012711012

Robinson, M. D., \& Clore, G. L. (2002). Belief and feeling: Evidence for an accessibility model of emotional self-report. Psychological Bulletin, 128, 934-960. doi:10.1037/0033-2909.128.6.934

Tett, R. P., Wang, A., Gribler, J., \& Martinez, A. (1997, April). Development of the self-report measures of emotional intelligence. Paper presented at the Annual Convention of the Southeastern Psychological Association, Atlanta, GA.

Tomlinson, J. M., Carmichael, C. L., Reis, H. T., \& Aron, A. (2010). Affective forecasting and individual differences: Accuracy for relational events and anxious attachment. Emotion, 10, 447-453. doi:10.1037/ a0018701

Tulving, E., \& Schacter, D. (1990). Priming and human memory systems. Science, 247, 301-306. doi:10.1126/science.2296719

Urry, H. L. (2010). Seeing, thinking, and feeling: Emotion-regulating effects of gaze-directed cognitive reappraisal. Emotion, 10, 125-135. doi: $10.1037 / \mathrm{a} 0017434$

Walsh, E., \& Ayton, P. (2009). What would it be like for me and for you? Judged impact of chronic health conditions on happiness. Medical Decision Making, 29, 15-22. doi:10.1177/0272989X08326147

Wechsler, D. (2008). Wechsler Adult Intelligence Scale: Technical and interpretive manual (4th ed.). San Antonio, TX: Pearson.

Wilson, T., Wheatley, T., Meyers, J., Gilbert, D., \& Axsom, D. (2000). Focalism: A source of durability bias in affective forecasting. Journal of Personality and Social Psychology, 78, 821-836. doi:10.1037/00223514.78.5.821

Wilson, T. D., Meyers, J., \& Gilbert, D. T. (2001). Lessons from the past: Do people learn from experience that emotional reactions are shortlived? Personality and Social Psychology Bulletin, 27, 1648-1661. doi:10.1177/01461672012712008

Received March 2, 2011

Revision received September 12, 2011

Accepted September 16, 2011 